\title{
NIVELES DE PROGESTERONA SÉRICA Y FECAL DURANTE EL CICLO ESTRUAL Y LA GESTACIÓN TEMPRANA EN YEGUAS
}

\author{
Tulita Alegría G. ${ }^{1}$, Victor Leyva.$_{.}{ }^{2}$ J Jorge Franco V. ${ }^{3}$
}

Serum and fecal progesterone levels during estrous and early gestation in mares

\begin{abstract}
$\mathrm{P}_{4}$ progesterone levels were determined in fecal samples from two non-pregnant and two pregnant mares at $0,4,8,16,24,36$ and 48 hours post defecation. Subsequently, fecal and serum $\mathrm{P}_{4}$ levels were studied during estrous and the first 50 days of gestation using 4 non-pregnant and 6 pregnant Arab mares. Blood and fecal samples were taken at the same time every other day for 100 days, and progesterone levels were determined by solid phase RIA. In the first group of 4 mares, fecal progesterone concentration decreased significantly $(p<0.01)$ from $26.76 \pm 5.24 \mathrm{ng} / \mathrm{g}$ at hour 0, to $3.7 \pm 1.2 \mathrm{ng} / \mathrm{g}$ at 48 hours post-excretion. For the second group, the correlation between fecal and serum $\mathrm{P}_{4}$ levels $(\mathrm{r}=0.96)$ was significant $(\mathrm{p}<0.01)$ during the estrous cycle $(\mathrm{r}=0.96)$ and first 50 days of gestation $(r=0.79)$. Overall $P_{4}$ level averages were lower $(p<0.05)$ during the follicular phase $(0.38 \pm 0.31 \mathrm{ng} / \mathrm{ml}$ for serum and $3.72 \pm 0.98 \mathrm{ng} / \mathrm{g}$ for feces) than during the luteal phase $(8.57 \pm 4.22 \mathrm{ng} / \mathrm{ml}$ for serum and $19.67 \pm 8.03 \mathrm{ng} / \mathrm{g}$ for feces $)$ of estrous, and significantly $(\mathrm{p}<0.05)$ lower during the first 25 days $(6.20 \pm 2.60 \mathrm{ng} / \mathrm{ml}$ for serum and $18.54 \pm 4.00 \mathrm{ng} / \mathrm{g}$ for feces) than during the subsequent 25 days $(8.39 \pm 3.86$ $\mathrm{ng} / \mathrm{ml}$ for serum and $21.4 \pm 4.74 \mathrm{ng} / \mathrm{g}$ for feces) of gestation. These results indicate that ovarian activity and early gestation in the mare can be reliably monitored by measurement of $\mathrm{P}_{4}$ levels in fecal samples.
\end{abstract}

Key words: Mare, progesterone, estrous, gestation, RIA.

Con el objeto de determinar los niveles de progesterona (P4) en heces de yeguas a diferentes intervalos de tiempo después de su evacuación, se colectaron muestras de heces de dos yeguas vacías y de dos preñadas y de éstas se tomaron submuestras a las $0,4,8,16,24,36$ y $48 \mathrm{~h}$ post-evacuación para ser procesadas por radioimmunoensayo (RIA). Los niveles de P4 (ng/g) descendieron en forma secuencial en relación al tiempo de muestreo después de su evaluación ( $p<0.05, p<0.01 ; p<0.001$ ), con el nivel mas alto encontrado a las $0 \mathrm{~h}(26.78 \pm 5.24 \mathrm{ng} / \mathrm{g})$ y el más bajo a las $48 \mathrm{~h}(3.71 .2 \mathrm{ng} / \mathrm{g})$. Basados en estos resultados se estudió la relación entre los niveles de $\mathrm{P}_{4}$ en la sangre $(\mathrm{ng} / \mathrm{ml})$ colectada de la vena yugular y en las heces $(\mathrm{ng} / \mathrm{g}$ ) colectada inmediatamente después de su evacuación $(0 \mathrm{~h})$, en 10 yeguas (cuatro fueron vacías y seis preñadas), para llevar a cabo este estudio durante el ciclo estrual y los primeros 50 días de gestación respectivamente. Los niveles de $\mathrm{P}_{4}$ en las heces siguieron el patrón de los niveles de $\mathrm{P}_{4}$ en el suero sanguíneo, con una correlación alta $(p<0.01)$ entre ellos durante el ciclo estrual $(r=0.96)$ y los 50 primeros días de gestación $(r=0.79)$. Como fue esperado,

\footnotetext{
${ }^{1}$ Práctica privada.

${ }^{2}$ Laboratorio de Reproducción- FMV-UNMSM

${ }^{3}$ Práctica privada.
} 
el nivel promedio general de $\mathrm{P}_{4}$ de la fase folicular en la sangre $(0.38 \pm 0.31 \mathrm{ng} / \mathrm{ml})$ y en las heces $(3.72 \pm 0.98 \mathrm{ng} / \mathrm{g})$ fue más bajo $(\mathrm{p}<0.01)$ que aquellas de la fase luteal $(8.57 \pm 4.22 \mathrm{ng} /$ $\mathrm{ml}$ y $19.67 \pm 8.03 \mathrm{ng} / \mathrm{g}$ respectivamente) y más baja ( $\mathrm{p}<0.05)$ durante los primeros 25 días $(6.20 \pm 2.61 \mathrm{ng} / \mathrm{ml}$ y $18.54 \pm 4.0 \mathrm{ng} / \mathrm{g}$ respectivamente) que aquellos en el subsecuente período de $26-50$ días $(8.39 \pm 3.80 \mathrm{ng} / \mathrm{ml}$ y $21.40 \pm 4.74 \mathrm{ng} / \mathrm{g}$ respectivamente) de gestación. Estos resultados demuestran la factibilidad de monitorear la actividad ovárica en el ciclo estrual y en la gestación temprana a través de la determinación de los niveles de $\mathrm{P}_{4}$ en las heces, como una técnica no-invasiva.

Palabras clave: Yegua, progesterona, ciclo estrual, gestación, RIA.

\section{-}

La progesterona $\left(\mathrm{P}_{4}\right)$ es producida mayormente en el ovario por las células del cuerpo lúteo, en la corteza de la glándula adrenal y por la placenta en los animales gestantes. La determinación de su concentración en la circulación periférica permite conocer la actividad ovárica durante el ciclo estrual e identificar preñez (Knickerbecker et al., 1988; Roberts, 1980; Hodgen y Itskovitz, 1988).

La $\mathrm{P}_{4}$ ejerce un efecto inhibitorio en la secreción y liberación pulsátil de la hormona liberadora de gonadotropinas $(\mathrm{GnRH})$ en el hipotálamo y consecuentemente en las hormonas gonadotrópicas de la hipófisis durante el ciclo estrual (Pamela et al., 1995).

Durante la gestación la $\mathrm{P}_{4}$ desempeña un rol preponderante en el establecimiento de la preñez y la implantación del embrión en el útero y del mismo modo favorece el desarrollo de la glándula mamaria asegurando la nutrición del nuevo ser después del nacimiento (Gerald y Albretch, 1995; Clark y Marcaverich, 1988).

La $\mathrm{P}_{4}$ antes de su excreción es previamente conjugada en el hígado para luego ser excretada como conjugado por la vía renal o vía digestiva en las heces (Wasser et al., 1991). Estudios en primates a los cuales se les suministró $\mathrm{P}_{4}$ marcada isotópicamente, encontraron por radioinmunoensayo (RIA) que un $32 \%$ de la $\mathrm{P}_{4}$ fue eliminada a través de las heces (Wasser et al., 1991). Este hallazgo permite realizar estudios sobre la actividad ovárica en los animales, mediante la determinación de la $\mathrm{P}_{4}$ en las heces, lo cual sería ventajoso ya que requiere menos manipulación de los animales que en el muestreo de sangre. Al respecto, se han realizado estudios en monos (Wasser et al., 1991; Shideler et al., 1993), felinos (Brown et al., 1994), en el diagnóstico de preñez en yeguas de vida silvestre (Kirkpatrick et al., 1991) y en la actividad del cuerpo lúteo en yeguas no preñadas de Equus caballus y Equus przewalski (Schwarzenberger et al., 1992). En línea con el interés antes anotado y considerando que la concentración fecal de $\mathrm{P}_{4}$ varía con el tiempo después de que las heces son evacuadas, y que los niveles presentes en las heces de yeguas vacías y preñadas tienen relación con aquellos que son registrados en el suero sanguíneo; se requiere clarificar es la variación de la $\mathrm{P}_{4}$ en heces procesadas a diferentes periodos después de su evacuación a fin de determinar el momento óptimo de muestreo y con base en este resultado determinar niveles de $\mathrm{P}_{4}$ en heces de yeguas durante el ciclo estrual y los 50 primeros días de preñez.

Se usaron animales del Centro de Reproducción Equina del Ejército, ubicado en el distrito de Barranco, en la provincia de Lima a una altitud de $150 \mathrm{msnm}$, latitud sur $12^{\circ} 05^{\prime}$, longitud oeste $77^{\circ} 02^{\prime}$. El Experimento se realizó del 14 de agosto al 14 de diciembre de 1997.

Para estudiar la variación de la concentración de $\mathrm{P}_{4}$ fecal, procesadas a diferentes intervalos post-evacuación se usaron he- 
ces de yeguas preñadas $(n=2)$ y vacías ( $n$ $=2$ ) de las cuales se tomaron sub muestras para su procesamiento a las $0,4,8,16,24,36$ y 48 horas post-evacuación.

Para la segunda fase experimental se seleccionaron 10 yeguas al azar, con un peso promedio de $450 \mathrm{~kg}$ y eđades cuyo rango estaba entre 4 a 10 años. Cuatro yeguas permanecieron vacías y en ellas se evaluó los diferentes ciclos estruales que presentaron durante los 100 días que duró el muestreo. Seis yeguas preñaron y en ellas se midió los niveles de $\mathrm{P}_{4}$ durante los 50 primeros días de preñez, el cual fue dividido en dos periodos de 0-25 y 26-50 días de preñez.

Para la medición de la $\mathrm{P}_{4}$ sérica se tomó $10 \mathrm{ml}$ de sangre por punción de la vena yugular entre las 11.00 a.m. a 1.00 p.m., en forma interdiaria. Las muestras fueron centrifugadas a $2500 \mathrm{rpm}$ durante 5 minutos para obtener el suero, el cual fue conservado en congelación a $-20^{\circ} \mathrm{C}$ hasta su posterior determinación hormonal.

Las muestras fecales fueron tomadas en forma simultánea que las muestras séricas, la cual una vez colectada fue homogenizada y de allí se tomó $50 \mathrm{~g}$, los cuales fueron desecados a $45^{\circ} \mathrm{C}$, molidos y tamizados; el polvo fecal obtenido fue guardado a temperatura ambiente en viales de vidrio herméticos y debidamente etiquetados.

El polvo fecal, previa a la determinación por radioimnunoensayo (RIA), fue sometido a un proceso de extracción de esteroides mediante solventes, método validado por Wasser et al. (1991) para tal fin.

Los niveles de $\mathrm{P}_{4}$ sérica y fecal se determinaron por RIA de fase sólida, utilizando kits comerciales DPC (Diagnostic Product Corporation, CA, Los Angeles). La sensibilidad del ensayo fue de $0.01 \mathrm{ng} / \mathrm{ml}$.

Para la fase experimental 1 , los datos fueron analizados por mediciones repetidas con prueba de análisis de varianza y la comparación de los promedios a diferentes tiempos después de su evacuación mediante la Prueba de Duncan (Steel y Torrie, 1990). En la fase experimental 2, los datos sobre niveles de $\mathrm{P}_{4}$ durante la fase folicular y luteal del ciclo estrual y durante 0 a 25 y 26 a 50 días de preñez fueron analizados mediante ANOVA, usando el paquete estadístico computarizadoSAS.

El grado de asociación entre la concentración de $\mathrm{P}_{4}$ fecal y sérica durante el ciclo estrual y los 50 primeros días de preñez fue establecida por correlación de Pearson.

Los cambios en la concentración de $\mathrm{P}_{4}$ fecal registrados a diferentes horas despues que las heces fueron evacuadas se muestran en la Figura 1, nótese que la mayor concentración se registró en las muestras colectadas inmediatamente después de su evacuación (0 horas) disminuyendo gradualmente en las muestras subsecuentes.

Las diferencias de los resultados entre hembras vacías y preñadas no fueron significativas, por consiguiente los datos de $\mathrm{P}_{4}$ fueron agrupados para establecer las diferencias en la concentración de $\mathrm{P}_{4}$ fecal a diferentes tiempos de muestreo fecal.

El resultado $(26.7 \pm 5.2 \mathrm{ng} / \mathrm{g})$ obtenido a las 0 horas fue significativamente mayor $(\mathrm{P}<0.05, \mathrm{P}<0.01)$ que las obtenidas a las $4(19.5 \pm 4.8 \mathrm{ng} / \mathrm{g}), 8(15.3 \pm 3.6 \mathrm{ng} / \mathrm{g}), 16$ $(9.3 \pm 3.7 \mathrm{ng} / \mathrm{g}), 24(8.9 \pm 7.2 \mathrm{ng} / \mathrm{g}), 36(8.2$ $\pm 2.3 \mathrm{ng} / \mathrm{g})$ y 48 horas $(3.7 \pm 1.2 \mathrm{ng} / \mathrm{g})$ post evacuación.

El promedio general de los niveles de $P_{4}$ durante el ciclo estrual, tanto séricos como fecales se muestran en el Cuadro 1; como era de esperarse los niveles de $\mathrm{P}_{4}$ durante la fase luteal fueron mayores que los de la fase folicular. En la Figura 2 se muestra el perfil de los niveles de $\mathrm{P}_{4}$ durante el ciclo estrual, donde los niveles plasmáticos durante la fase 


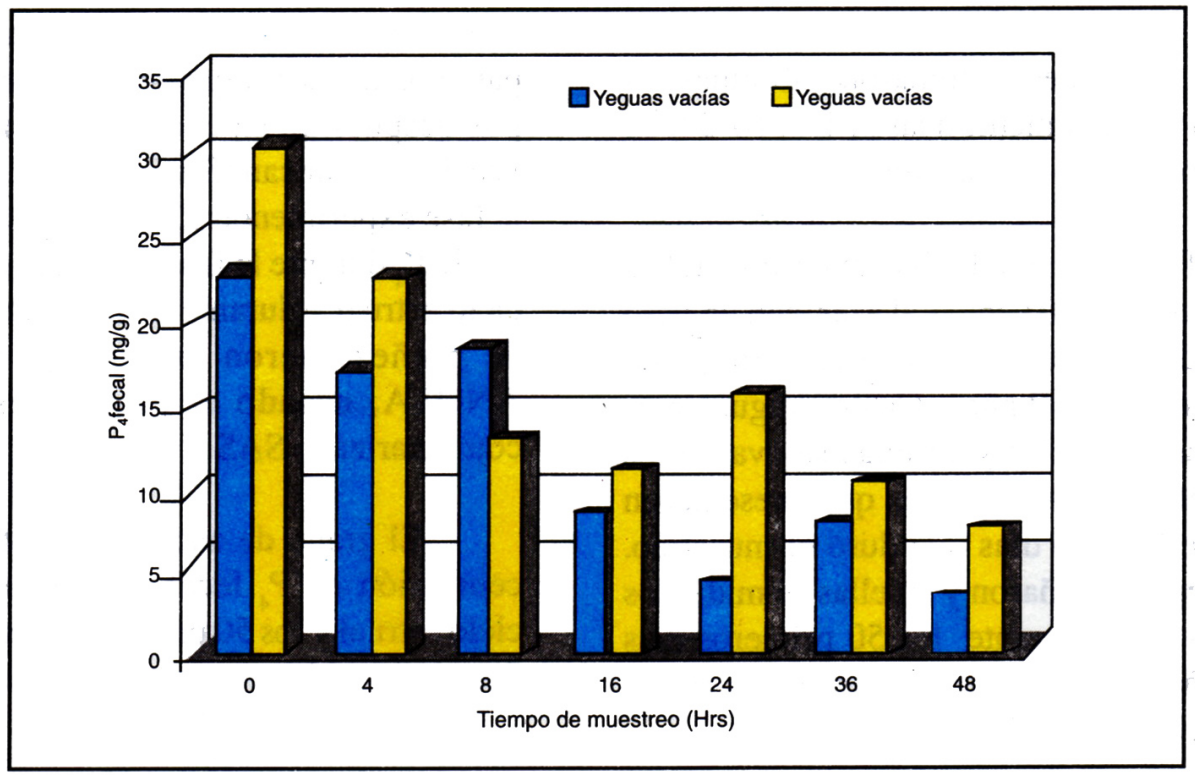

Figura 1. Niveles de $\mathrm{P}_{4}$ fecal a diferentes tiempos después de su excreción en yeguas vacías y preñadas.

folicular está por debajo de $1 \mathrm{ng} / \mathrm{ml}$ y los niveles fecales por debajo de $3.18 \mathrm{ng} / \mathrm{g}$ y estos se incrementan después de la ovulación alcanzando picos en los siguientes 5 a 8 días; para luego disminuir y alcanzar los niveles basales el día 15 en ambos casos. Nótese que mientras la tendencia de los niveles fecales y séricos fue similar, la curva de los niveles fecales mostró que tanto el pico máximo como el descenso de los niveles de $\mathrm{P}_{4}$ ocurrieron más tardíamente en comparación con lo ocurrido en los niveles séricos.

La correlación ( $r=0.96)$ entre los niveles séricos y fecales fue altamente significativa $(P<0.01)$ durante el ciclo estrual.

Cuadro 1. Niveles de progesterona sérica (ng/ml) y fecal (ng/g) durante el ciclo estrual en la yegua.

\begin{tabular}{lcc}
\hline Progesterona & \multicolumn{2}{c}{ Fases del ciclo estrual } \\
\cline { 2 - 3 } & Folicular & Luteal \\
& $\mathrm{X} \pm \mathrm{ES}$ & $\mathrm{X} \pm \mathrm{ES}$ \\
\hline Sérica & $0.38 \pm 0.31^{\mathrm{a}}$ & $8.57 \pm 4.22^{\mathrm{b}}$ \\
Fecal & $3.72 \pm 0.98^{\mathrm{a}}$ & $19.67 \pm 8.03^{\mathrm{b}}$ \\
\hline
\end{tabular}

Letras diferentes en la misma línea indican diferencia estadística significativa $(\mathrm{P}<0.05)$.
En el Cuadro 2 se muestran los resultados de las determinaciones de $\mathrm{P}_{4}$ sérica y fecal durante los 50 primeros días de preñez. Nótese que hubo diferencias significativas $(\mathrm{P}<0.05)$ en la concentración de $\mathrm{P}_{4}$ entre los periodos de 0-25 días y 26-50 días de preñez tanto a nivel sérico $(6.20 \pm 2.61 \mathrm{ng} /$ $\mathrm{ml}$ vs $8.4 \pm 3.9 \mathrm{ng} / \mathrm{g})$ como fecal $(18.5 \pm 4.0$ $\mathrm{ng} / \mathrm{ml}$ vs $21.4 \pm 4.7 \mathrm{ng} / \mathrm{g}$ ).

En la Figura 3 se observa el perfil de los promedios de niveles séricos de $\mathrm{P}_{4}$ de las yeguas preñadas durante los 50 primeros días de preñez, donde el día 0 corresponde a la ovulación. Durante los primeros días de preñez, los niveles séricos de $\mathrm{P}_{4}$ se incrementan

Cuadro 2. Niveles de progesterona sérica (ng/ml) y fecal (ng/g) durante los 50 primeros días de preñez en yeguas.

\begin{tabular}{lcc}
\hline Progesterona & \multicolumn{2}{c}{ Periodos de preñez (Días) } \\
\cline { 2 - 3 } & $\begin{array}{cc}0-25 \\
\mathrm{X} \pm \mathrm{EE}\end{array}$ & $\begin{array}{c}26-50 \\
\mathrm{X} \pm \mathrm{EE}\end{array}$ \\
\hline Sérica & $6.20 \pm 2.61^{\mathrm{a}}$ & $8.39 \pm 3.86^{\mathrm{b}}$ \\
Fecal & $18.54 \pm 4.00^{\mathrm{a}}$ & $21.40 \pm 4.74^{\mathrm{b}}$
\end{tabular}

Letras diferentes en la misma línea indican diferencia estadística significativa $(\mathrm{P}<0.05)$. 


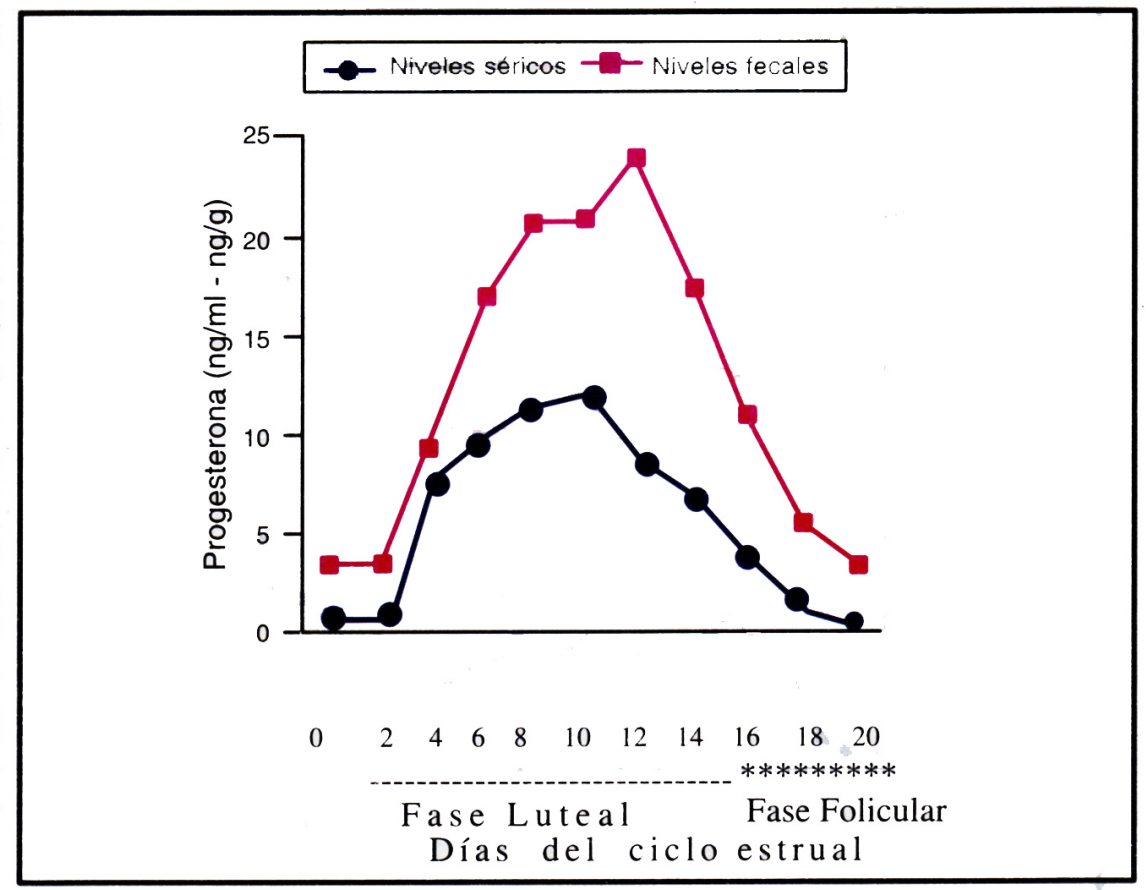

Figura 2. Relación entre la concentración promedio de $\mathrm{P}_{4}$ sérica y fecal durante el ciclo estrual en yeguas.

después de la ovulación y alcanza el primer pico entre los 8 y 12 días; luego. sufre una relativa disminución irregular hasta el día 38 para luego incrementarse hasta el día 50 de preñez. El perfil de $\mathrm{P}_{4}$ fecal mostró un patrón similar, con la diferencia que el primer pico ocurrió entre los días 10 y 20 de la preñez. Los picos de incremento ocurren más tardíamente que aquellos registrados en el suero sanguíneo.

La correlación ( $r=0.79)$ entre los valores de $\mathrm{P}_{4}$ fecal y sérica fue estadísticamente significativa $(\mathrm{P}<0.01)$ durante los 50 primeros días de preñez.

\section{Discusión}

La disminución de la concentración de $\mathrm{P}_{4}$ fecal en hembras vacías y preñadas a través del tiempo después de la evacuación es un hallazgo que se informa por primera vez en yeguas. De acuerdo al patrón observado, es posible que las concentraciones fecales de $\mathrm{P}_{4}$ no sean detectables después de un cierto tiempo post-evacuación de las heces. Estos resultados plantean la necesidad de estandarizar la obtención de las muestras de heces a un tiempo fijo después de la excreción para estudios de seguimiento de la función ovárica a fin de no incurrir en errores de interpretación de los resultados. Esta disminución puede deberse a una posible metabolización y/o degradación por la microflora fecal y a procesos de evaporación y filtración junto con el agua que se elimina de las heces en el proceso de desecación en el medio ambiente.

Se conoce que la $\mathrm{P}_{4}$ que es conjugada en el hígado se elimina con la orina y las heces (Rodríguez, 1995; Shwarzenberger et al., 1992; Wasser et al., 1991); y al igual que otros elementos después de ser excretados sufren procesos de reducción u oxidación al contacto con el aire del medio ambiente y por efecto de algunos microorganismos fecales (Rodríguez, 1995; Shideler et al., 1993). 


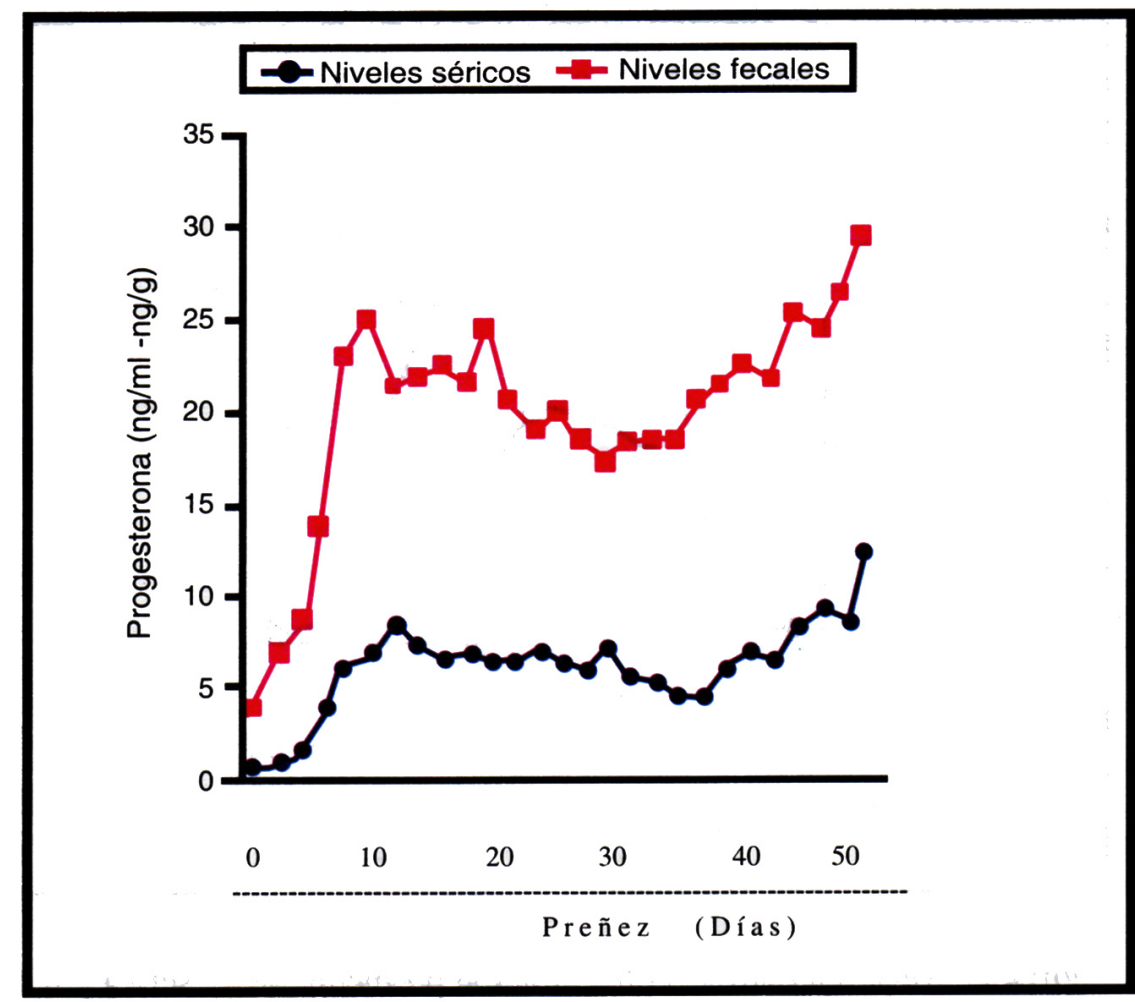

Figura 3. Relación entre la concentración promedio de $\mathrm{P}_{4}$ sérica fecal durante los 50 primeros días de preñez en yeguas.

Los coeficientes altos de correlación entre niveles de $P_{4}$ fecal y sérica durante el ciclo estrual $(r=0.96)$ y los 50 primeros días de preñez $(r=0.79)$ nos indica que los niveles fecales están estrechamente relacionados con los niveles séricos y sugiere que su medición representa una herramienta confiable para monitorear los cambios fisiológicos que ocurren durante el ciclo estrual y la gestación en yeguas. Estos resultados confirman correlaciones positivas entre esteroides fecales y séricos durante estadios de preñez y no preñez descritas por otros autores en yeguas de vida silvestre y otras especies (Wasser et al; 1991; Brown et al; 1994; Kirkpatrick et al;1991, Morrow y Monfort, 1998).

La relación estrecha entre el perfil de la concentración de $\mathrm{P}_{4}$ sérica y fecal durante la fase folicular y la fase luteal del ciclo estrual y la gestación temprana, sugieren que los niveles de $\mathrm{P}_{4}$ fecal reflejan la fases clásicas de la actividad secretoria del cuerpo lúteo durante el ciclo estrual (Harry, 1988; Noden et al., 1978; Knickerbecker et al; 1988; Hafez, 1993) y la preñez (Brown et al; 1994; Kirkpatrick et al., 1991).

La diferencia en el tiempo y momento de ocurrencia de los picos de $\mathrm{P}_{\text {q }}$ que sucedieron más tardíamente a nivel fecal con relación al sérico se debe por la diferencia en el tiempo de secreción más rápida de la $\mathrm{P}_{4}$ al torrente sanguíneo y más tardía de excreción de la $\mathrm{P}_{4} \mathrm{y} / \mathrm{o}$ sus metabolitos para aparecer en las heces intestinales (Schwarzenberger et al., 1992; Morrow y Monfort, 1998).

En la gestación temprana, la producción de $P_{4}$ observado tanto a nivel sérico como fecal en el periodo de 0-25 días de preñez, refleja la actividad secretoria del cuerpo lúteo primario, importante para el establecimiento e implantación del embrión (Ireland, 1987). La producción de $\mathrm{P}_{4}$ en el periodo de 26-50 días de preñez involucra la actividad secretoria del cuerpo lúteo pri- 
mario y de los cuerpos lúteos secundarios que se originan por efecto de la PMSG secretada por las copas endometriales a partir de los 38 días de gestación (Heap y Flint, 1984; Ireland, 1987).

La concentración fecal de $\mathrm{P}_{4}$ fue mayor que la sérica durante el ciclo estrual y la gestación temprana; similares resultados en otras especies han sido informados (Wasser et al., 1991; Brown et al., 1994; Kirkpatrick et al., 1991; Schwarzenberger et al., 1992). Esta diferencia podría ser explicada por la mayor concentración de $\mathrm{P}_{4}$ en las muestras fecales que fueron obtenidas inmediatamente después de su evacuación.

La concentración de $\mathrm{P}_{4}$ fecal disminuye a medida que aumenta el tiempo entre la excreción y la colección de la muestra.

El alto grado de asociación entre las muestras fecales y séricas, permite estudiar el estado fisiológico de las yeguas mediante la determinación de $\mathrm{P}_{4}$ en heces obtenidas a un tiempo fijo después de su evacuación.

Los niveles de $\mathrm{P}_{4}$ determinados en las heces obtenidas inmediatamente después de su evacuación fueron mayores que los niveles medidos en suero sanguíneo.

1. Brown, J.; K. Wasser y D. E. Wildt. 1994. Comparative aspects of steroid hormone metabolism and ovarian activity in felids measured noinvasively in feces. Biology of Reprod. 51:776-786.

2. Clark, J. H. y B. H. Marcaverich. 1988. "Actions of ovarian steroid hormones". In The Physiology of Reproduction, pp. 675-719, edit by E. Knobil and J. Neil. Raven Press Itd., New York.
3. Gerald, J. P. y E. D. Albretch. 1995. Actions of placental and fetal adrenal steroid hormones in primate pregnancy. Endocrine Review. 16:608-634.

4. Hafez, E.S. 1993. Reproduction in farm animals, $6^{\text {th }}$ edition. Edit. Interamericana México, p. 573.

5. Heap R. B. y A. P. F. Flint. 1984. Pregnancy in Reproduction in Mammals. Hormonal control of reproduction CR. New York. p. 152-192.

6. Harry, L 1988. "Mechanism of mammalian ovulation". In: The Physiology of Reproduction. Edited by E. Knobil and J. Neil Raven. Press Rtd New York pp 447-481.

7. Hodgen, G. D. y J. Itskovitz. 1988. "Recognition and maintenance of pregnancy". In: the Physiology of Reproduction, edited by Knobil and J. Neil Raven. Press Ltd. New York, pp. 1995-2012.

8. Ireland, J.J. 1987. Control of follicular growth and development. J. Reprod. Fert. Suppl 34:38-54.

9. Kirkpatrick, J.F.; S.E. Shideler y J.W. Turner. 1991. Pregnancy determination in uncaptured feral horses by means of fecal steroid conjugates. Theriogenology 35:753-759.

10. Knickerbecker, J. J.; M. C. Wiltbank y G. D. Niswender. 1988. Mechanisms of luteolisis in domestic livertock. Domestic Anim. Endocrinol. 5:91-107.

11. Morrow, C. J. y S. L. Monfort. 1998. Ovarian activity in the scimitar-horned oryx (Oryx dammah) determined by faecal steroid analysis. Anim. Reprod. Sci. 53:191-207.

12. Noden, P. A.; W. D. Oxender y H. D. Hafz. 1978. Early changes in serum progesterone, estradiol and $\mathrm{LH}$ during prostaglandin $\mathrm{F}_{2 \alpha}$ induced luteolisis in mares. J. Animal Sci. 47:666-671. 
13. Pamela J. S.; L. M. Stephen y P. F. Batty. 1995.' Pulsatile Gonadotropin Secretion Determined by frequent sampling form the intercavernous sinus of the mare, possible modulatory rol of progesterone during luteolisis. Biology of Reproduction. 53:438-446.

14. Rodríguez, V.R. 1995. "Reproducción en equinos". En: Fisiología Veterinaria por García Sacristán A , Castijón Mf De la Cruz Palomino LF. Editorial Interaméricana. Madrid. España, pp. 19291969.

15. Roberts, S.J . 1980. "Gestation and pregnancy diagnosis in the mare". In: Current therapy in Theriogenology, Diagnosis, treatment and prevention of reproductive diseases in animals. Edited by Morrow A David. WB. Saunders Comp. London, pp. 736-745.

16. Shideler, S. E.; A. M. Ortuño y B. J. Lasley. 1993. Simple extraction and enzime inmunoassay for estrogen and progesterone metabolites in the feces of Macaca fascicularis during non concep- tive and conceptive ovarian cycles. Biol. Reprod. 48:1290-1298.

17. Shideler, S. E.; F. M. Moran y P. Stauffer. 1993. Enzime inmunoassays for ovarian steroid metabolites in the urine of Macaca fascicularis. J. Med. Primatol. 22:301-312.

18. Steel, R. G. D. y J. H. Torrie. 1990. Bioestadística, principios y procedimientos. 2a. ed., p. 263-273. Editorial McGrawHill, México.

19. Schwarzenberger, F.; E. Mostl.; E. Bamberg y G. Von HegeL 1992. Monitoring of corpus luteum function by measuring progestagens in faeces of nonpregnant mares (Equus caballus) and Przewalski mares (Equus przewalski). Anim. Reprod. Sci. 29:263-273.

20. Wasser, S. K.; S. L. Monfort y D. E. Wildt. 1991. Rapid extraction of fecal steroids for measuring reproductive cyclicity and early pregnancy in freeranging Yellow baboom. J. Reprod. Fert. 92:415-423. 